ARTICLE

DOI: $10.1038 / 541467-017-01625-x$

\title{
Both Nodal signalling and stochasticity select for prospective distal visceral endoderm in mouse embryos
}

\author{
Katsuyoshi Takaoka²,2, Hiromi Nishimura, ${ }^{1,2}$ \& Hiroshi Hamada1,2
}

Anterior-posterior (A-P) polarity of mouse embryos is established by distal visceral endoderm (DVE) at embryonic day (E) 5.5. Lefty1 is expressed first at E3.5 in a subset of epiblast progenitor cells ( $L 1^{\text {epi }}$ cells) and then in a subset of primitive endoderm cells ( $L 1^{\text {dve }}$ cells) fated to become DVE. Here we studied how prospective DVE cells are selected. Lefty1 expression in $\mathrm{L}^{\mathrm{epi}}$ and $\mathrm{L} 1^{\mathrm{dve}}$ cells depends on Nodal signaling. A cell that experiences the highest level of Nodal signaling begins to express Lefty1 and becomes an L1 ${ }^{\text {epi }}$ cell. Deletion of Lefty1 alone or together with Lefty2 increased the number of prospective DVE cells. Ablation of $L 1^{\text {epi }}$ or $L 1^{\text {dve }}$ cells triggered Lefty1 expression in a subset of remaining cells. Our results suggest that selection of prospective DVE cells is both random and regulated, and that a fixed prepattern for the A-P axis does not exist before the blastocyst stage.

\footnotetext{
${ }^{1}$ Developmental Genetics Group, Graduate School of Frontier Biosciences, Osaka University, 1-3 Yamada-oka, Suita, Osaka 565-0871, Japan. ${ }^{2}$ RIKEN Center for Developmental Biology, 2-2-3 Minatojima-minamimachi, Chuo-ku, Kobe, Hyogo 650-0047, Japan. ${ }^{3}$ Present address: Max Planck Institute for Biophysical Chemistry, Am Fassberg 11, 37077 Gottingen, Germany. Correspondence and requests for materials should be addressed to

K.T. (email: katsuyoshi.takaoka@mpibpc.mpg.de) or to H.H. (email: hiroshi.hamada@riken.jp)
} 
n Drosophila, the anterior-posterior (A-P) body axis is specified by maternal determinants that are asymmetrically distributed within the oocyte with respect to future A-P polarity ${ }^{1}$. Such maternal determinants do not appear to exist for mammals such as the mouse, however, with the mechanism by which $\mathrm{A}-\mathrm{P}$ polarity is established in these animals having remained unknown. A-P polarity is established in the mouse embryo when the distal visceral endoderm (DVE) migrates toward the future anterior side at embryonic day (E) 5.5 (refs. ${ }^{2-7}$ ). Concomitant with DVE migration, all visceral endoderm (VE) cells in the a
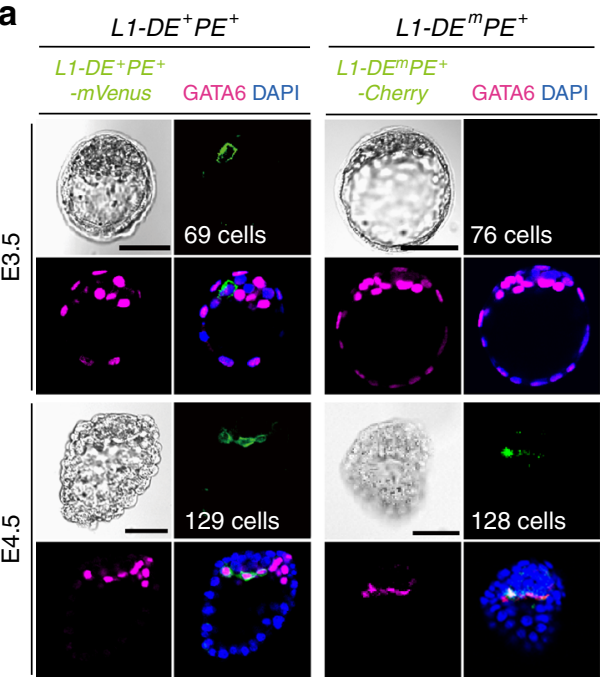

b $_{1 \mathrm{~kb}}$

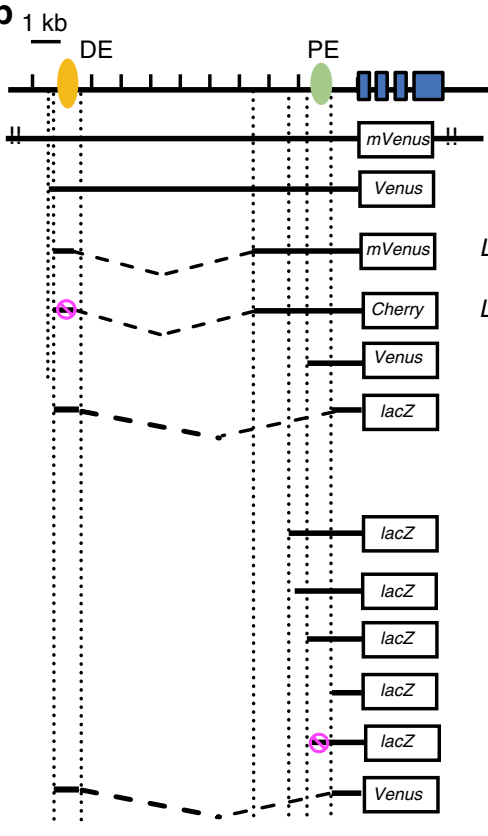

$L 1-D E^{+}$
$L 1-P E^{+}$

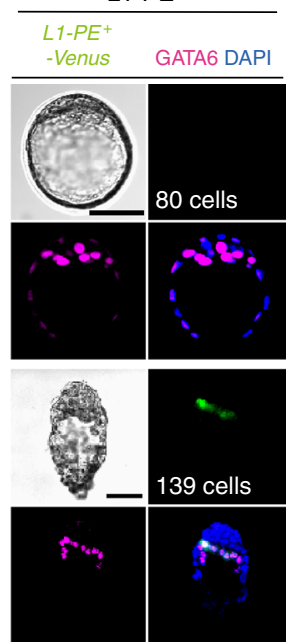

C
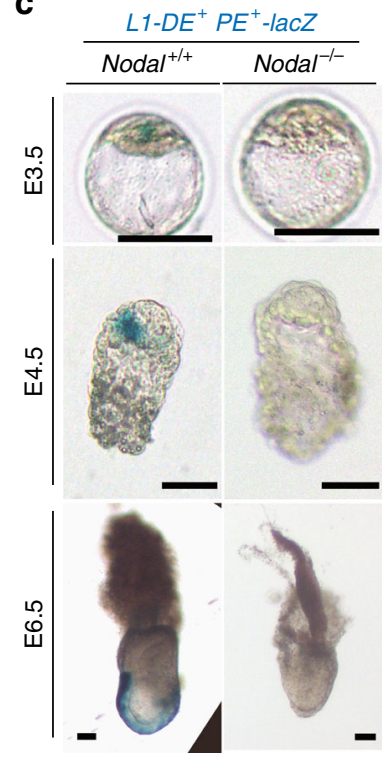

$L 1-10.5 \quad+\quad++\quad++\quad++$

$L 1-D E^{+} P E^{+}++\quad++++\quad++++\quad++++$

$\angle 1-D E^{m} P E^{+} \quad-\quad++\quad-\quad-$

$\angle 1-P E^{+}-\quad++\quad-\quad-$

$L 1-D E^{+}+$Ectopic Ectopic Ectopic

L1-2.5 $\quad \frac{\begin{array}{c}\text { E4.5 transient assay } \\ \left.\text { (normal /ectopic } / \mathrm{Tg}^{+}\right)\end{array}}{++(3 / 0 / 15)}$

L1-2.2 ++ (7/0/32)

$L 1-P E^{+} \quad++(7 / 0 / 28)$

L1-1.0 - $(0 / 0 / 38)$

$\angle 1-P E^{m} \quad-(0 / 2 / 43)$

E6.5

ectopic $(0 / 4 / 4)$

d

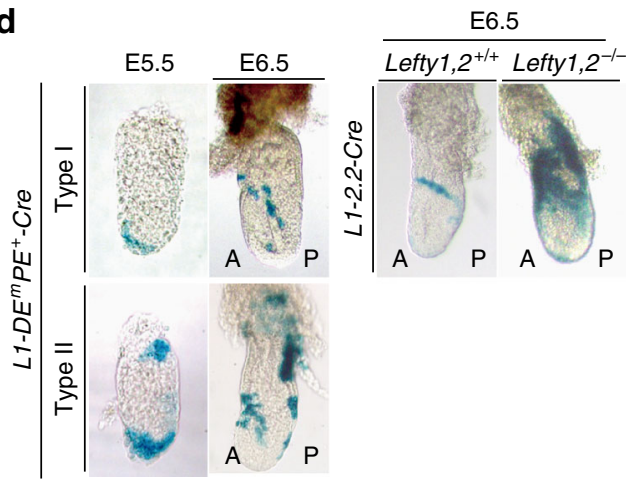


embryonic region undergo global movement, resulting in the localization of some VE cells at the distal tip of the embryo. These VE cells at the distal tip will become the anterior visceral endoderm (AVE) and migrate toward the future anterior side of the embryo by following the migration of $\mathrm{DVE}^{8}$. Development of the $\mathrm{A}-\mathrm{P}$ axis is thus a self-organizing process that does not require maternal cues. ${ }^{9,10}$

Whereas A-P polarity of the mouse embryo is firmly established during the period from E5.5 to E6.5, its origin can be traced back to preimplantation stages of development. Lefty1 is a marker of both DVE and AVE, but its expression begins in the blastocyst. It is expressed first in a subset of epiblast progenitor cells and then in a subset of primitive endoderm $(\mathrm{PrE})$ progenitors, the latter of which is fated to become DVE. Expression of Lefty1 therefore marks prospective DVE cells in peri-implantation embryos ${ }^{8}$. Although generation of Lefty $1^{+}$ future DVE cells ${ }^{9}$ and Cerl1 ${ }^{+}$DVE cells ${ }^{10,11}$ occurs in an embryoautonomous manner, generation of fully functional DVE may require interaction with the uterus ${ }^{12}$. Whereas Nodal signaling ${ }^{13}$ and expression of its target gene Eomes ${ }^{14}$ are essential for DVE formation, it has remained unknown how Leftyl expression is induced and how prospective DVE cells are selected in periimplantation embryos. In this study, we have now addressed these questions by studying the regulation of Lefty1 expression and its role in specification of future DVE cells. Our results suggest that selection of prospective DVE cells in mouse peri-implantation embryo is both random and regulated.

\section{Results}

Lefty1 expression is regulated by Nodal signaling. We have previously shown that Leftyl is expressed first (at E3.5) in a subset of epiblast progenitor cells and then (between E3.75 and E4.5) in a subset of PrE progenitors fated to become $\mathrm{DVE}^{8}$, with these Lefty $1^{+}$cell subsets being herein designated $\mathrm{L}^{\text {epi }}$ cells and $\mathrm{L}^{\text {dve }}$ cells, respectively. Some DVE cells were previously reported to be derived from epiblast (Sox $2^{+}$cells) that transmigrates into $\mathrm{VE}^{12}$. We examined this possibility by testing whether Oct $3 / 4^{+}$and Sox $2^{+}$epiblast contributes to DVE. We were unable to detect Oct3/4 (mTomato) $)^{+}$cells (7/7 embryos at E5.5), Oct3/4 ${ }^{+}$ cells $\left(14 / 14\right.$ embryos at E5.5) or $\mathrm{Sox2}^{+}$cells (4/4 embryos at E5.5, 5/5 embryos at E6.0) in the DVE region (Supplementary Fig. 1), however, suggesting that all DVE cells are derived from L1 ${ }^{\text {dve }}$ cells between E3.75 and E4.5, as we previously described $^{8}$.

We examined how Lefty1 expression is regulated in both $\mathrm{L}_{1}{ }^{\mathrm{epi}}$ and $\mathrm{L} 1$ dve cells (Fig. 1). A Lefty1(mVenus or Cherry) bacterial artificial chromosome (BAC) transgene that recapitulates Lefty1 expression in embryos ${ }^{8}$ was active in epiblast progenitor cells ${ }^{8}$ within the inner cell mass (ICM) of E3.5 embryos and in the PrE of E4.5 embryos ${ }^{8,9}$ (Supplementary Fig. 2a, b, c), representing
Lefty1 expression in $\mathrm{L} 1^{\mathrm{epi}}$ and $\mathrm{L} 1^{\mathrm{dve}}$ cells, respectively. L1-10.5Venus, a transgene that contains the $10.5-\mathrm{kb}$ upstream region of Lefty1 and which recapitulates Lefty1 expression at E6.5 and E8.0 (refs. ${ }^{9,15}$ ) (Fig. 1b), was also active at E3.5 (presumably in L1 ${ }^{\text {epi }}$

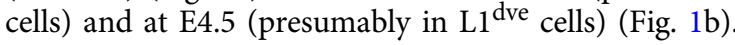

Given that left-right (L-R) asymmetric expression of Lefty1 at E8.0 is regulated by Nodal-Foxh1 signaling ${ }^{15}$, we examined the possible role of such signaling in Lefty1 expression at E3.5 and E4.5. Culture of E3.2 embryos harboring a Lefty1(mVenus) BAC transgene with the Nodal signaling inhibitor SB431542 for $24 \mathrm{~h}$ prevented the emergence of Lefty1 expression (11/11 embryos) (Supplementary Fig. 2h). Foxh1-binding sequences that are conserved between mouse and human ${ }^{9}$ are present within the 10.5-kb upstream region of Lefty1, with two such sequences being located in the region around $-1.5 \mathrm{~kb}$ and two in the region around $-10 \mathrm{~kb}\left(\right.$ ref. $\left.{ }^{9}\right)$. Foxh1 binding has been detected at both of these regions in human embryonic stem cells by chromatin immunoprecipitation-sequencing (ChIP-seq) analysis ${ }^{16,17}$ (Supplementary Fig. 2i). The Foxh1-dependent enhancers located at -10 and $-1.5 \mathrm{~kb}$ of Lefty 1 are hereafter referred to as DE (distal enhancer) and PE (proximal enhancer), respectively.

The $L 1-D E^{+} P E^{+}-m$ Venus transgene, which contains $\mathrm{DE}$ and $\mathrm{PE}$, was active in a few epiblast progenitor cells at E3.5 (L1 ${ }^{\text {epi }}$ cells) and in GATA6 ${ }^{+}$cells in PrE at E4.5 (L1 ${ }^{\text {dve }}$ cells) (Fig. 1a, b,

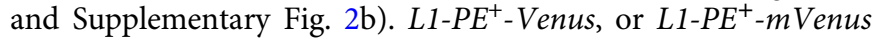
which contains PE but lacks DE, was inactive in the ICM at E3.5 but active in a few $\mathrm{GATA}^{+}$cells of $\operatorname{PrE}$ at E4.5 ( ${ }^{\text {dve }}{ }^{\text {cells) }}$ (Fig. 1a, b, and Supplementary Fig. 2c). Similarly, L1-PE $E^{+}$-lacZ was inactive at E3.5, active at E4.5, and inactive at E6.5 (Supplementary Fig. 2e). L1-DE transgenes were active in the ICM at E3.5 but showed ectopic expression in the epiblast between E4.5 and E6.5 (Fig. 1b and Supplementary Fig. 2f, g). L1$D E^{+} P E^{+}$-lacZ was not expressed at E3.5, E4.5, or E6.5 in Nodal $^{-1-}$ embryos (11/12 embryos at E3.5, 8/8 embryos at E4.5, 2/2 embryos at E6.5) (Fig. 1c), suggesting that the activity of both $\mathrm{DE}$ and PE is Nodal dependent. Consistent with this notion, L1$D E^{\mathrm{m}} P E^{+}$-Cherry or $L 1-D E^{\mathrm{m}} P E^{+}$-lacZ, in which the Foxh1-binding sites of $\mathrm{DE}$ are mutated, was inactive at $\mathrm{E} 3.5$ but was active at $\mathrm{E} 4.5$ (Fig. 1a, b, and Supplementary Fig. 2d), whereas $L 1-P E^{\mathrm{m}}$-lac $Z$, in which the Foxh1-binding sequences of $\mathrm{PE}$ are mutated, was not active at E4.5 (Fig. 1b). Furthermore, SB431542 abolished expression of $L 1-D E^{+} P E^{+}$-mVenus (6/6 embryos) and L1-PE $E^{+}$-Venus (4/4 embryos) in E3.2 embryos cultured for $24 \mathrm{~h}$ (Supplementary Fig. 2h).

L1-DE ${ }^{\mathrm{m}} P E^{+}$-Cre, a Cre transgene driven by PE, marked DVE at E5.5 and DVE-derived cells at E6.5 but failed to label epiblast at both stages (24/24 embryos) (Fig. 1d). Similarly, L1-2.2-Cre, which contains PE, specifically marked DVE-derived cells, excluding the epiblast, at E6.5 (6/7 embryos) (Fig. 1d). Together, these results suggested that the Foxh1-binding sites in DE are essential for Lefty1 expression in $\mathrm{L1}^{\mathrm{epi}}$ cells of the ICM at E3.5,

Fig. 1 Lefty1 expression in $\mathrm{L}^{\mathrm{epi}}$ and $\mathrm{L}^{\mathrm{d} \text { dve }}$ cells is regulated by Nodal-Foxh1 signaling. a Expression of three Lefty1 transgenes ( $L 1-D E^{+} P E^{+}-m V e n u s$, L1-DE ${ }^{m} P E^{+}$-Cherry, and $L 1-P E^{+}-$Venus) was examined in mouse embryos at E3.5 and E4.5. Embryos were immunostained for transgene expression as well as for GATA6 (a PrE-specific marker), and they were counterstained with 4',6-diamidino-2-phenylindole (DAPI). Bright-field images are also shown. The expression pattern of $L 1-D E^{+} P E^{+}-$lac $Z$ in wild-type embryos has been described previously ${ }^{8}$. The number of cells in each embryo is indicated. Scale bars, 50 $\mu \mathrm{m}$. $\mathbf{b}$ Structures of various Lefty 1 reporter transgenes and summary of their activities at the indicated stages. $L 1-B A C$ is the Lefty $1(m V e n u s) B A C$ transgene generated by replacement of lacZ in the Leftyl(lacZ) BAC transgene ${ }^{9}$ with mVenus. The positions of two Foxh1-dependent enhancers, DE (distal enhancer) and $P E$ (proximal enhancer), are indicated. The Foxh1-binding sites in DE or PE are mutated in $L 1-D E^{m} P E$ and $L 1-P E^{m}$, respectively. c The expression of

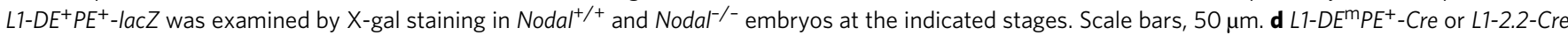
transgenic mice were crossed with Rosa26R transgenic mice, and transgenic embryos recovered at E5.5 or E6.5 were stained with X-gal. Two types of

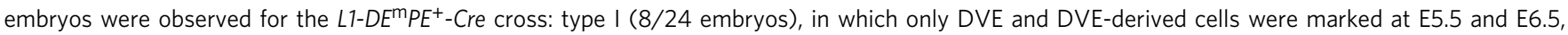
respectively; and type II (16/24 embryos), in which the extraembryonic region was positive in addition to DVE and DVE-derived cells at E5.5 and E6.5. DVE-derived cells were detected on the lateral side of E6.5 embryos produced from the L7-2.2-Cre cross (6/7 embryos). The number of DVE-derived cells was increased in E6.5 embryos produced from a cross of L1-2.2-Cre mice with Lefty1,2/- mice expressing Rosa26R (2/3 embryos) 
whereas the Foxh1-binding sites in PE regulate Lefty1 expression in $\mathrm{L}^{\text {dve }}$ cells at E4.5. DE may also contribute to the regulation of Lefty1 expression at E4.5, given that the expression level of L1-DE $P E^{+}$-lac $Z$ at this time (Supplementary Fig. 2d) was lower than that of $L 1-D E^{+} P E^{+}$-lacZ (Fig. 1c) (note that the LacZ staining time for the former embryo was $12 \mathrm{~h}$, whereas that for the latter embryo was $15 \mathrm{~min}$ ).

Nodal signaling induces Lefty1 expression. Given that our results suggested that Nodal-Foxh1 signaling regulates Lefty1 a

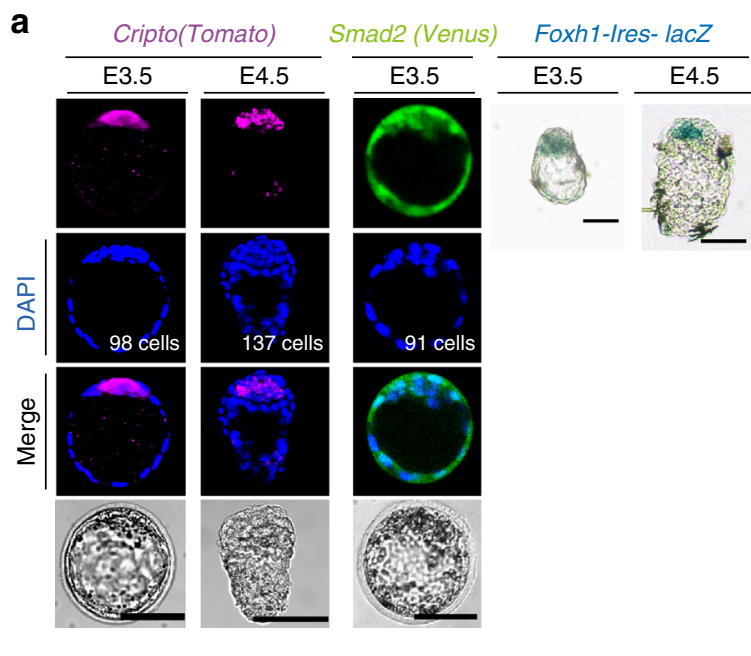

C

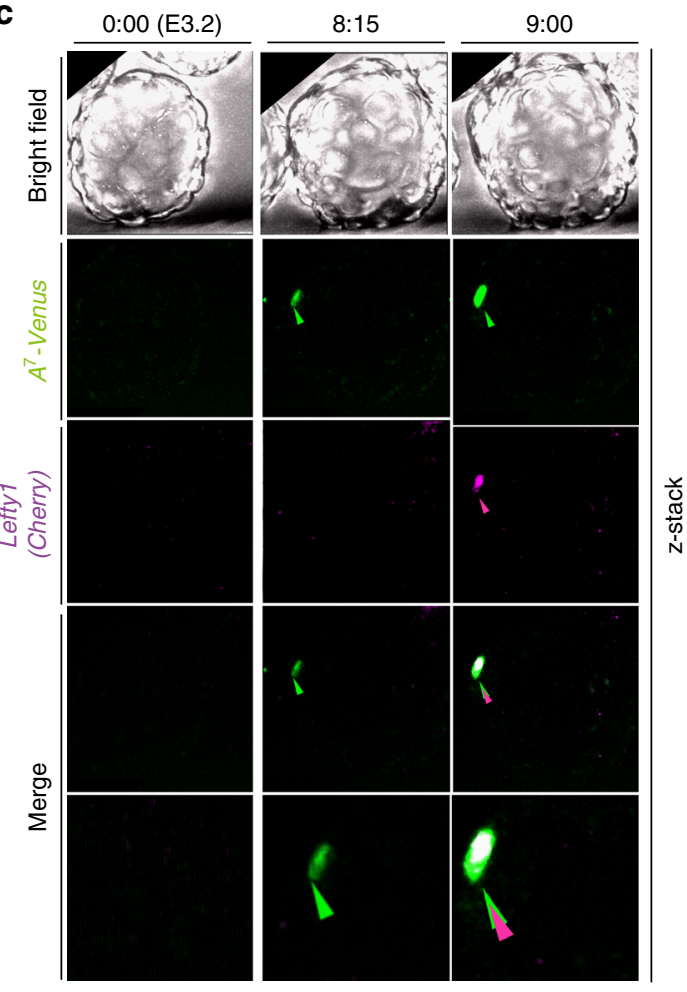

d

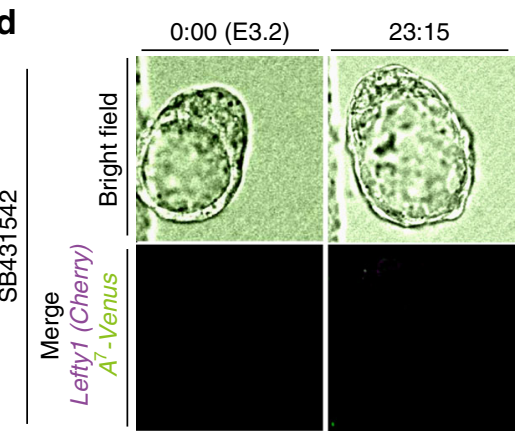

b

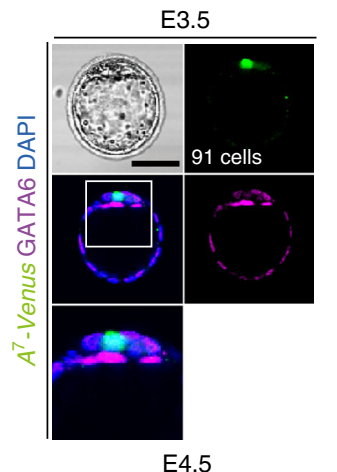

E4.5
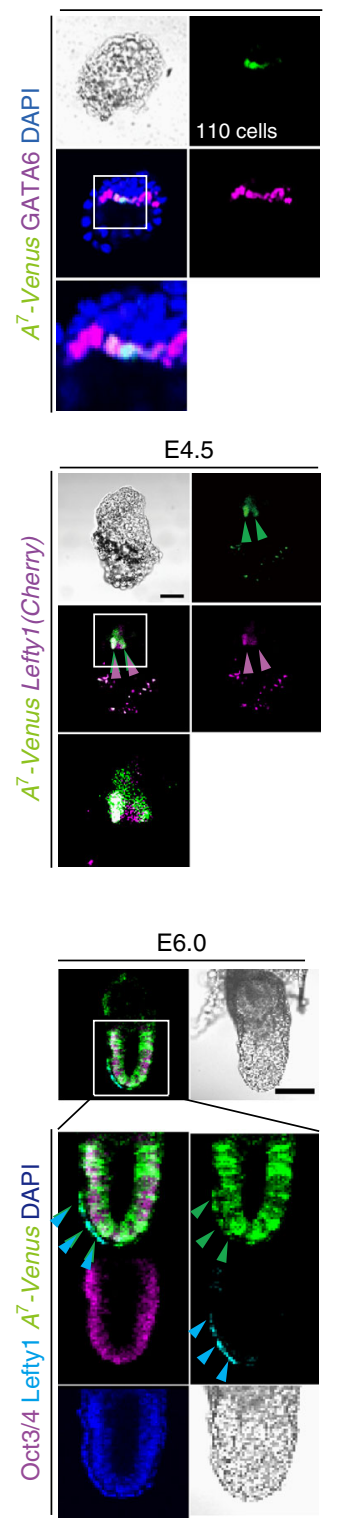
expression in $\mathrm{L}^{\text {epi }}$ and $\mathrm{L}^{\mathrm{dve}}$ cells, we next examined expression of Nodal signaling components. Cripto (E3.5: 5/5 embryos; E4.5: 6/6 embryos), Foxh1(E3.5: 4/5 embryos; E4.5: 8/8 embryos), and Smad2(E3.5: 6/7 embryos) were all found to be expressed between E3.5 and E4.5 (Fig. 2a) ${ }^{9}$. Nodal-Foxh1 signaling activity can be monitored with a transgene driven by seven tandem repeats of a Foxh1-binding sequence ${ }^{18}$. When examined with such a transgene, $A_{7}$-Venus, Nodal-Foxh1 signaling was found to be active in a few ICM cells at E3.5 (presumably L1 ${ }^{\text {epi }}$ cells, 11/11 embryos), in a few GATA6 ${ }^{+}$cells at E4.5 (L1 ${ }^{\text {dve }}$ cells, given that they also expressed Lefty1, 12/14 embryos), and in AVE and epiblast cells at E6.0, as expected (10/10 embryos) (Fig. 2b). Culture of E3.2 embryos for $24 \mathrm{~h}$ with SB431542 prevented $A_{7^{-}}$ Venus expression (11/11 embryos) (Supplementary Fig. 3a), whereas it was maintained in the control embryos (5/5 embryos), confirming that such expression is dependent on Nodal signaling. Simultaneous monitoring of both $A_{7}$-Venus and Lefty 1 expression in live embryos from E3.2 revealed that a single cell became positive for Venus expression after culture for $\sim 8 \mathrm{~h}$ (Fig. 2c, Supplementary Movie 1). This cell then began to express Lefty1. Lefty $1^{+}$cells in such live imaging at this time (equivalent to E3.5) were positive for Venus (15/16 embryos), which is consistent with the notion that Lefty 1 expression in $\mathrm{L} 1{ }^{\text {epi }}$ cells is induced by Nodal signaling. Furthermore, expression of $A_{7}$-Venus and Lefty 1 (Cherry) was abolished in the presence of SB431542 (Fig. 2d, Supplementary Movie 2). Lefty $1^{+}$cells at E4.5 were also positive for Venus (7/7 embryos) (Fig. 2b), suggesting that Lefty1 expression in $\mathrm{L1}^{\mathrm{dve}}$ cells is also regulated by Nodal signaling. While Lefty1 expression was found in $\mathrm{PrE}$ at E4.5, Cripto was not expressed in PrE (Fig. 2a). It is most likely that PrE cells can receive Nodal siganing because Cryptic, another co-receptor for Nodal, is expressed in $\operatorname{PrE}^{19}$, and because Cripto and Cryptic can act non-cell-autonomously ${ }^{20,21}$. In support of this, Lefty $1^{+}$cells at E5.5 (DVE cells) are lost in the Cripto ${ }^{-1-}$, Cryptic $^{-/-}$double mutant embryo $^{19}$.

We next monitored Nodal and Lefty1 expression simultaneously in live embryos between E3.2 and E4.0 (Fig. 3a, Supplementary Movie 3). Nodal expression, as revealed with a Nodal(Tomato) BAC transgene, was dynamic, beginning in one cell, rapidly expanding to all cells, and being maintained until E4.0. Lefty1 expression (in L1 ${ }^{\text {epi }}$ cells) was found to begin in the same cell that had earlier initiated Nodal expression (12/24 embryos) or in a neighboring cell (11/24 embryos).

We also examined the effect of ectopic Nodal expression on Lefty1 expression. Injection of Nodal mRNA and mTomato mRNA into E3.2 embryos harboring the Lefty1( $m$ Venus) BAC transgene and examination of the embryos $6 \mathrm{~h}$ later revealed that Lefty1 expression began either in the cell that received Nodal mRNA (6/19 embryos) or in a neighboring cell (12/19 embryos) (Fig. $3 \mathrm{~b}-\mathrm{e})$. In the remaining embryo (1/19 embryos), Lefty 1 expression was found in a distant cell. Injection of Nodal mRNA did not increase the number of Lefty $1^{+}$cells at E4.5 (Fig. $3 \mathrm{f}$ and
Supplementary Fig. 3b, c). When Nodal mRNA and mTomato mRNA (encoding a membrane-localized form of Tomato) were injected into E3.2 embryos harboring the $A_{7}$-Venus transgene, Venus was detected in the cell that received Nodal mRNA or in a neighboring cell (Fig. 3g). We confirmed that Nodal protein was produced in the excess injected cell (Fig. $3 \mathrm{~h}$ ). When mTomato mRNA alone was injected, however, Venus ${ }^{+}$cells were located randomly relative to the $\mathrm{mTomato}^{+}$cell (Fig. $3 \mathrm{~d}$, e). Collectively, these results suggested that Lefty 1 expression in $\mathrm{L}^{\text {epi }}$ and $\mathrm{L}_{1}^{\mathrm{dve}}$ cells is induced by Nodal-Foxh1 signaling.

Lefty activity restricts the number of prospective DVE cells. We next investigated whether Lefty proteins might play a role in DVE formation. In addition to Lefty1, Lefty 2 was also expressed in mouse embryos between E3.5 and E4.5. Expression of Lefty2, as revealed with a Lefty2(lacZ) BAC transgene, was thus detected in a subset of ICM cells at E3.5 (Supplementary Fig. 4a, b: 16/16 embryos). At E4.5, Lefty2 was expressed in a subset of $\operatorname{PrE}$ and EPI cells (Supplementary Fig. 4b). Lefty2 expression at E4.5 was also dependent on Nodal-Foxh1 signaling, given that such expression was not apparent in Nodal $^{-1-}$ (3/3 embryos) or Foxh1 $1^{-l-}$ (4/4 embryos) embryos (Supplementary Fig. 4a). Monitoring of Lefty2 and Lefty1 expression from E3.2 also revealed that both genes were expressed in the same ICM cells (L1 ${ }^{\text {epi }}$ cells) (6/10 embryos) (Supplementary Fig. 4b and Supplementary Movie 4) or in different ICM cells (4/10 embryos). Both genes also initiated their expression with similar timing (Supplementary Fig. 4c and Supplementary Movie 4). Given that Lefty 2 was also found to be expressed in ICM cells at E3.5, we generated a mutant (Lefty1,2 $2^{-/}$) mouse lacking both Lefty1 and Lefty2 (Supplementary Fig. 5a). Staining of Lefty $1,2^{-1-}$ embryos with antibodies that recognize both Lefty 1 and Lefty 2 confirmed the absence of Lefty proteins (5/5 embryos) (Supplementary Fig. 5b).

We then examined the effect of Lefty 1 and Lefty 2 deletion on the number of future DVE cells. Prospective DVE cells were identified and counted in Lefty1(mVenus) BAC transgenic embryos at E4.5 (Fig. 4a). The number of future DVE cells (mVenus $^{+}$cells) was increased in the absence of Lefty genes (Fig. 4a, d, e, and Supplementary Table 2), whereas the number of PrE cells (Fig. 4b, Supplementary Table 2) or ICM cells (Fig. 4c, Supplementary Fig. 5, and Supplementary Table 2) was not significantly affected. mVenus $^{+}$cells thus constituted $\sim 10 \%$ of total PrE cells (GATA6 ${ }^{+}$cells) in wild-type (WT) embryos, whereas they accounted for 25 to $30 \%$ of $\mathrm{PrE}$ cells in some Left $y 1^{-/-}$embryos (Fig. 4e, Supplementary Table 2). This finding is consistent with our previous observation that the number of cells expressing Cerl1 (a marker for DVE) at E5.5 was increased in Lefty $1^{-7-}$ embryos $^{22}$. Moreover, future DVE cells accounted for $30-50 \%$ of PrE cells in Lefty $1,2^{-/-}$embryos (Fig. 4e, Supplementary Table 2). These results suggested that Leftyl is not only a

Fig. 2 Lefty1 expression begins in cells positive for Nodal-Foxh1 signaling. a Expression of Nodal signaling components in mouse embryos at E3.5 and E4.5. Expression of Cripto(Tomato) and Smad2(Venus) BAC transgenes as well as that of GATA6 were monitored by immunofluorescence staining, whereas that of a Foxh1-Ires-lacZ transgene was monitored by X-gal staining. Scale bars, $50 \mu \mathrm{m}$. b Embryos harboring $A_{7}$-Venus were examined for Venus and GATA6 immunofluorescence at E3.5 and E4.5 (top two panels). Note that Venus is expressed in a GATA6 ${ }^{-}$cell at E3.5 and in GATA6 ${ }^{+}$cells at E4.5. An E4.5 embryo harboring $A_{7}$-Venus and a Lefty1(Cherry) BAC transgene was examined for Venus and Cherry immune fluorescence (third panel). Arrowheads indicate two Lefty $1^{+}$cells that are also positive for Venus. An E6.0 embryo harboring $A_{7}$-Venus was subjected to immunofluorescence staining for $V e n u s$, Lefty, and Oct3/4 (bottom panel). Arrowheads indicate Cherry in magenta, Venus in green and Lefty1 in light blue. Boxed regions are shown at higher magnification in the images immediately below. Scale bars, $50 \mu \mathrm{m}$. c An E3.2 embryo harboring both Lefty 1 (Cherry) and $A_{7}-$ Venus transgenes was cultured for $9 \mathrm{~h}$. Fluorescence of Venus and Cherry was examined at the indicated times. A single cell positive for Venus was detected at $8.25 \mathrm{~h}$ (arrowhead). This cell had being positive for Cherry at $9 \mathrm{~h}$. d An E3.2 embryo harboring both Lefty1(Cherry) and $A_{7}$-Venus transgenes was cultured for $23.15 \mathrm{~h}$ in the presence of $10 \mu \mathrm{M}$ SB431542 and monitored for Venus and Cherry fluorescence. Note that Venus or Cherry fluorescence is not apparent at $23.15 \mathrm{~h}$ 
marker for future DVE cells in the blastocyst, but that it also restricts the number of prospective DVE cells together with Lefty2. Although the number of prospective DVE cells was increased in Lefty1, $2^{-/-}$embryos at E4.5, the expression patterns of Cerl1 and Hex appeared normal at E6.5 (9/9 embryos for Cerl1, 6/6 embryos for Hex) and E7.5 (5/5 embryos for Cerl1) (Supplementary Fig. 5d, e), suggesting that AVE is formed normally even though such AVE cells lack Leftyl. Since Cerl1 is required to position the primitive streak at the posterior side of the embryo ${ }^{23}$, together with Lefty1 and Lefty2, Cerl1 may have a redundant role in AVE formation.

Nodal-Lefty regulatory network. Our results indicated that Lefty 1 expression is induced by Nodal signaling and that Lefty 1 a

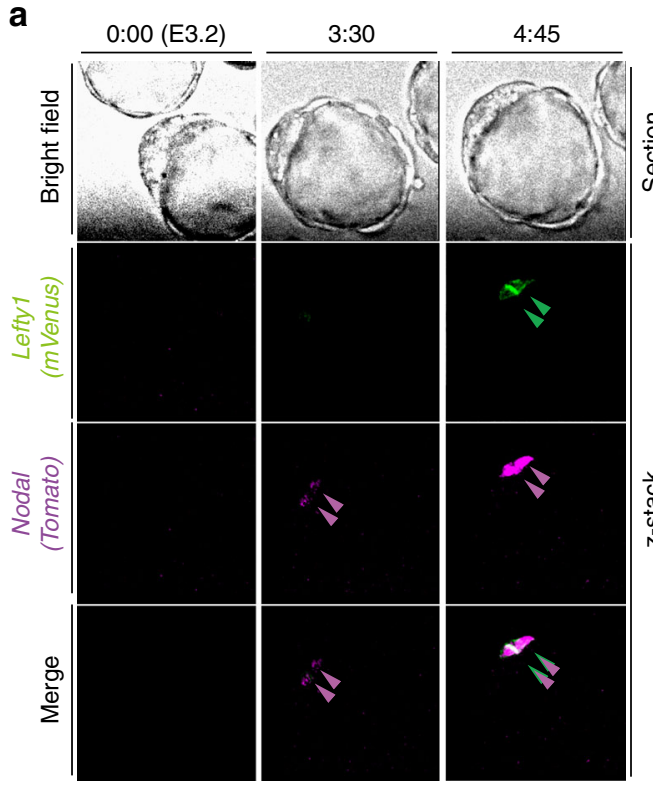

b

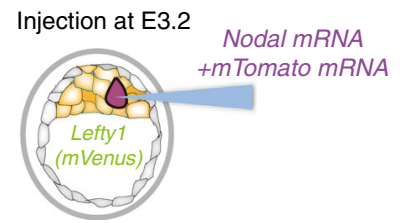

C

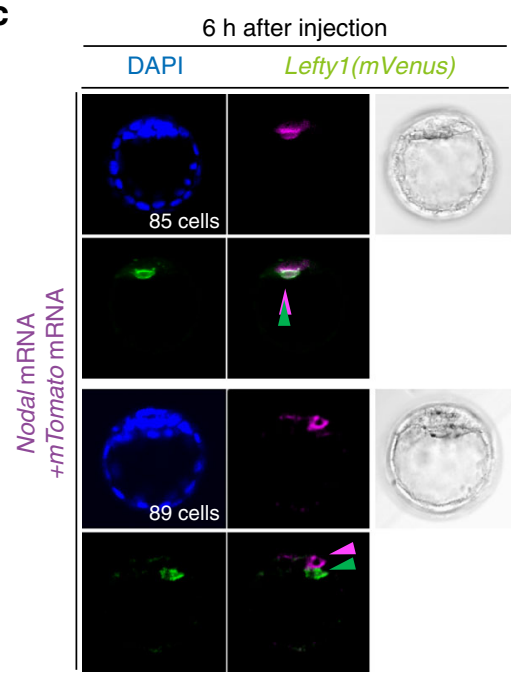

d

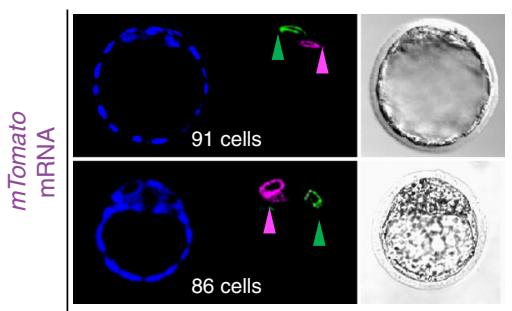

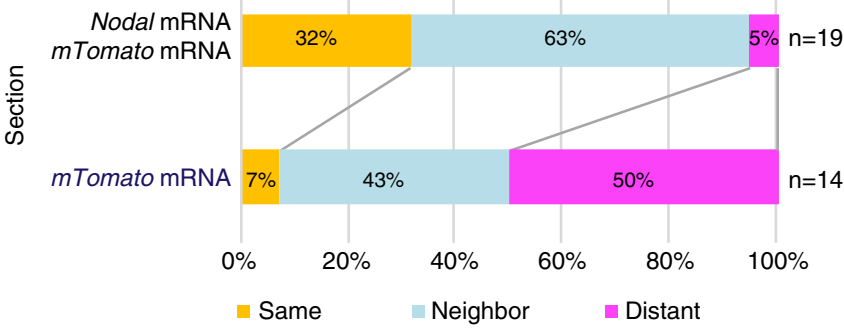

f

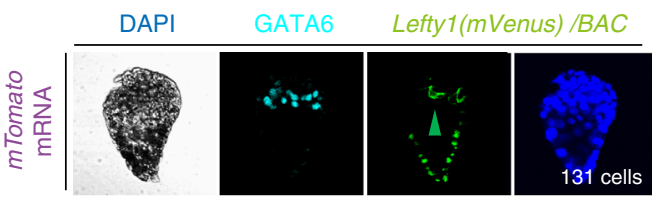

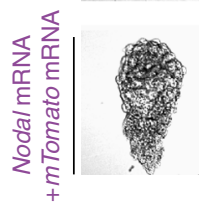

g
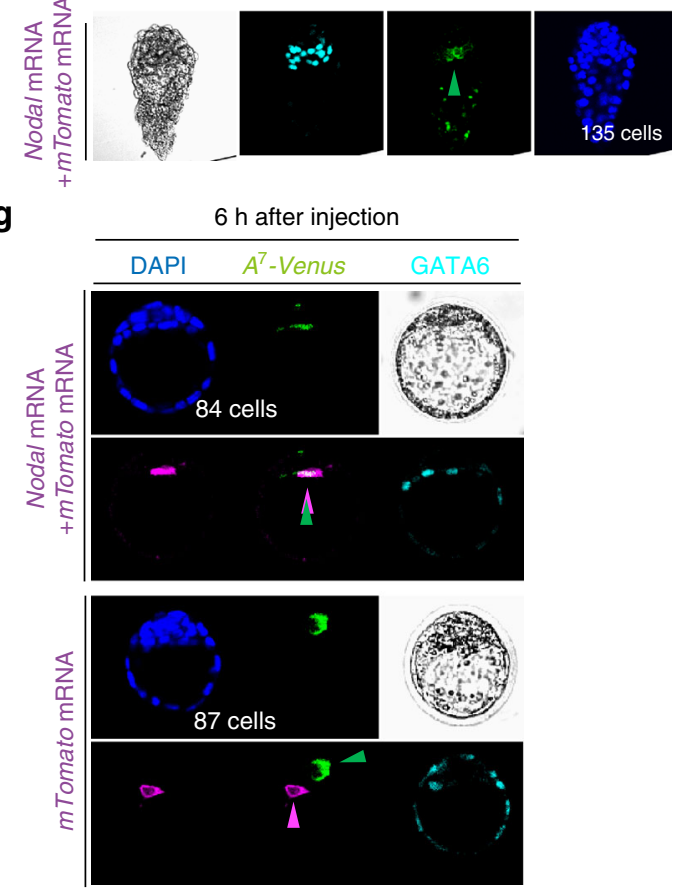

h

Nodal mRNA cherry mRNA Nodal

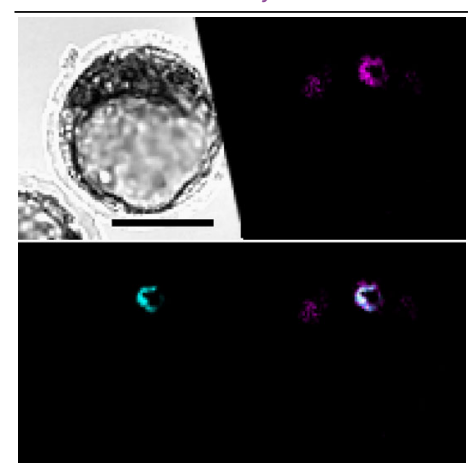


restricts the number of Lefty $1^{+}$cells, a scenario reminiscent of the self-enhancement and lateral inhibition (SELI) Nodal-Lefty regulatory network that operates during L-R patterning at E8.0 ${ }^{24}$. Given that Lefty proteins diffuse faster than Nodal ${ }^{25}$, whether a Nodal-Lefty SELI system operates in peri-implantation embryos will depend on whether Nodal expression is positively regulated by Nodal itself. We therefore investigated how Nodal expression is regulated at the blastocyst stage-in particular, whether it is positively autoregulated as it is at E8.0. Transcription of Nodal is regulated by several enhancers, including two Foxh1-dependent enhancers, $\operatorname{ASE}^{26,27}$ and $\mathrm{LSE}^{27}$, which contribute to L-R asymmetric expression of Nodal at E8.0 (Fig. 5a) and which are also active at the peri-implantation stage ${ }^{28}$. Another enhancer, PEE, whose activity depends on Wnt- $\beta$-catenin signaling, is also active in a subset of cells in the blastocyst ${ }^{28}$.

We found that ASE, LSE, and PEE all contribute to the regulation of Nodal expression at E4.5. Deletion of ASE thus attenuated Nodal expression (14/15 embryos) (Fig. 5b). Whereas additional deletion of LSE did not have a further substantial effect on Nodal expression (17/19 embryos), which of both LSE and PEE did further reduce it (7/10 embryos) (Fig. 5b). Given that ASE and LSE are dependent on Foxh1 and that PEE is dependent on Wnt- $\beta$-catenin, these results suggested that Nodal expression in peri-implantation mouse embryos is positively regulated by Nodal signaling. Consistent with this notion, culture of E3.2 embryos with SB431542 for $24 \mathrm{~h}$ resulted in marked attenuation of Nodal expression, presumably in $\mathrm{L}_{1}{ }^{\mathrm{epi}}$ and $\mathrm{L}_{1}{ }^{\text {dve }}$ cells (13/13 embryos) (Fig. 5c). Furthermore, Nodal expression in $\mathrm{L}_{1}{ }^{\text {dve }}$ cells at E4.5 was greatly reduced in Foxh1 ${ }^{-1-}$ embryos (4/4 embryos) (Fig. 5d). Together, these observations suggested that Nodal expression in peri-implantation embryos is positively regulated by Nodal signaling via Foxh1-dependent enhancers (Fig. 5e).

$\mathrm{L1}^{\mathrm{epi}}$ and $\mathrm{L1}^{\mathrm{dve}}$ cells are selected randomly. Injection of Nodal mRNA into a single cell at E3.2 induced Lefty1 expression in the same cell, generating an $\mathrm{L} 1^{\text {epi }}$ cell (Fig. 3c), but it did not increase the overall number of $\mathrm{L1}^{\mathrm{epi}}$ cells (Supplementary Fig. 3b, c). When such injected embryos were returned to the uterus and allowed to develop further, they developed normally at least up to E6.5 (5/5 embryos), showing normal expression patterns of Cerl1, Lefty1, and Lefty2 (Fig. 6a). Both Cerl1 and Lefty1 were thus detected at the anterior side, suggesting that the AVE was formed normally. Lefty 2 was expressed at the opposite (posterior) side, suggesting that the primitive streak was formed correctly. Examination of the fate of the injected cell revealed that it survived and contributed to DVE and DVE-derived cells at E6.5 (Fig. 6b). We also removed all (usually two or three) Lefty ${ }^{+}$cells from Lefty1(mVenus) transgenic embryos at E3.5 by laser ablation. Cell ablation was confirmed by monitoring of the cell membrane, with successful ablation resulting in rupture of the membrane and the appearance of fluorescent cell debris (Fig. 6c). Culture of the ablated embryos revealed that Lefty 1 was expressed in a different cell by $8 \mathrm{~h}$ after the ablation (8/8 embryos) (Fig. 6c). On return to the uterus, such ablated embryos again developed an apparently normal A-P axis by E6.5, with Lefty1 and Cerl1 expression being apparent on the anterior side of the embryo and Lefty2 expression on the posterior side (10/10 embryos) (Fig. 6d).

Similarly, when all (usually four or five) $\mathrm{L}^{\text {dve }}$ cells at $\mathrm{E} 4.0$ were ablated, a new Lefty $1^{+}$cell appeared in the PrE region by $8 \mathrm{~h}$ after the ablation (Fig. 7a). On return of such embryos to the uterus, they developed an apparently normal A-P axis by E6.5 (Fig. 7b).

Together, these results suggested that both $\mathrm{L}_{1}{ }^{\mathrm{epi}}$ and $\mathrm{L1}^{\text {dve }}$ cells are not predetermined but are selected in a regulated and robust manner. Furthermore, the A-P axis can be established normally even if an ectopic cell begins to express Lefty1 between E3.5 and E4.0; that is, an ectopic cell can be specified to become a prospective DVE cell.

\section{Discussion}

Lefty1 is expressed first in L1 ${ }^{\text {epi }}$ cells at E3.5 and subsequently in L1 ${ }^{\text {dve }}$ cells. Although Lefty 1 expression specifically marks future DVE cells in the mouse embryo at E4.0 to E4.5, it is not absolutely required to specify DVE cells, given that $\mathrm{Cerl}^{+} \mathrm{Hex}^{+}$cells are formed at E6.5 in the absence of both Lefty1 and Lefty2. Rather, Lefty1 and Lefty 2 function to restrict the number of future DVE cells. Thus, in the absence of either Lefty1 alone or both Lefty1 and Lefty2, the number of future DVE cells is increased at E4.5. The number of DVE cells at E5.5 (Cerl1-expressing cells) was previously shown to be increased in Lefty $1^{-/-}$embryos $^{22}$. However, we found that the number and position of AVE cells at E6.5 (Cerl1-expressing cells) remained essentially normal in Lefty $1,2^{-1-}$ embryos. Although DVE guides the anterior migration of AVE cells that arise later, the increased number of DVE cells in the mutant embryos does not appear to influence the appearance and migration of AVE cells.

Then, why does Lefty1 expression occur in two steps? In particular, what is the role of the first phase of Lefty 1 expression in $\mathrm{L}_{1}{ }^{\mathrm{epi}}$ cells? Lefty1 expression in $\mathrm{L1}^{\mathrm{epi}}$ cells is transient, disappearing shortly after $\mathrm{L}^{\text {dve }}{ }^{\text {cells }}$ arise ${ }^{8}$. Lefty 1 produced in $\mathrm{L}_{1}{ }^{\mathrm{ep}}$ cells may establish an uneven distribution of Nodal activity within the blastocyst, as revealed by the pattern of $A_{7}$-Venus expression at E3.5 (Fig. 2c), and thereby allow only one or two cells to become $\mathrm{L}_{1}{ }^{\mathrm{epi}}$ cells (Fig. 7c). This would in turn restrict the number of $\mathrm{Ll}^{\text {dve }}$ cells and determine the position of these cells in the blastocyst. In support of this notion, $\mathrm{L}^{\text {dve }}$ cells arise in a

Fig. 3 Lefty1 expression in L1 ${ }^{\text {epi }}$ cells is induced by Nodal. a An E3.2 embryo harboring both Lefty1( $m$ Venus) and Nodal(Tomato) BAC transgenes was cultured for $5 \mathrm{~h}$, with fluorescence of mVenus and Tomato being examined at the indicated times. Nodal expression began in two cells at $3.5 \mathrm{~h}$ (magenta arrowheads), with these two cells becoming positive for Lefty 1 expression by $4.75 \mathrm{~h}$ (green arrowheads). b Schematic illustration of mRNA injection experiments in (c) and (d). mTomato mRNA (encoding a membrane-localized Tomato) was injected with or without Nodal mRNA into a single cell of E3.2 embryos harboring the Lefty1(mVenus) BAC transgene. Embryos were examined for mTomato and mVenus immunofluorescence $6 \mathrm{~h}$ after mRNA injection. c Embryos injected with both mTomato and Nodal mRNAs. mVenus is expressed in the injected cell (upper panel) or in a neighboring cell of the injected cell (lower panel). d Two embryos injected with mTomato mRNA alone. TTomato $^{+}$and $\mathrm{mVenus}^{+}$cells (arrowheads) do not overlap. e Summary of the location of the $\mathrm{mVenus}^{+}$cell relative to the injected cell for experiments similar to that in $\mathbf{c}$ and $\mathbf{d}$. $\mathbf{f}$ E3.2 embryos harboring the Lefty 1 ( $m$ Venus) BAC transgene were injected with mTomato mRNA alone or together with Nodal mRNA, allowed to develop in utero, recovered at E4.5, and examined for Lefty1( $m$ Venus) and GATA6 expression. Note that there is no substantial difference in the number of Lefty7-expressing cells between the two types of injected embryos (Supplementary Fig. $3 b, c$ ). $\mathbf{g}$ E3.2 embryos harboring $A_{7}$-Venus were injected with mTomato mRNA alone or together with Nodal mRNA and were examined for GATA6 and Venus expression after $6 \mathrm{~h}$. When mTomato mRNA alone was injected, the Venus ${ }^{+}$cell was randomly located relative to the injected cell (lower panel). However, when Nodal mRNA was co-injected, the injected cell or a neighboring cell was positive for Venus (upper panel). $\mathbf{h}$ An E3.2 embryo co-injected with excess Nodal mRNA $(200 \mathrm{ng} / \mu \mathrm{l})$ and with mTomato mRNA was immunostained for Nodal at $6 \mathrm{~h}$ after mRNA injection. Scale bar, $50 \mu \mathrm{m}$ 
a

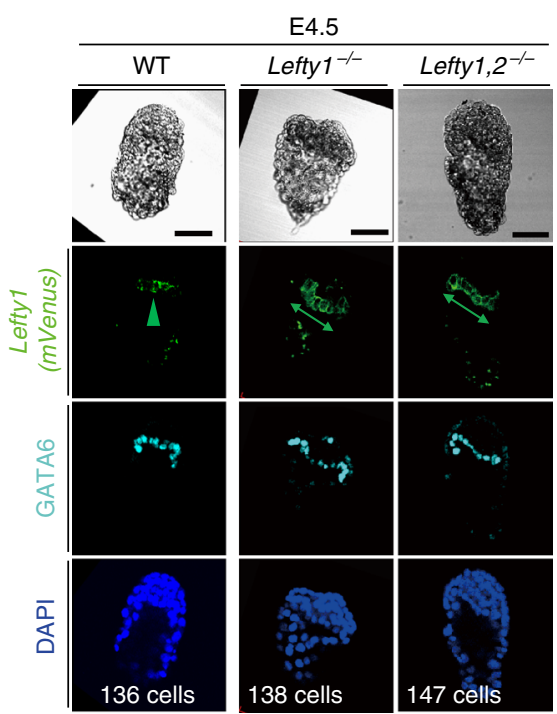

b

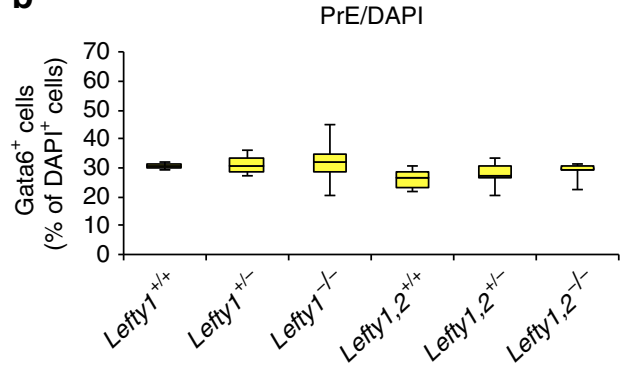

d

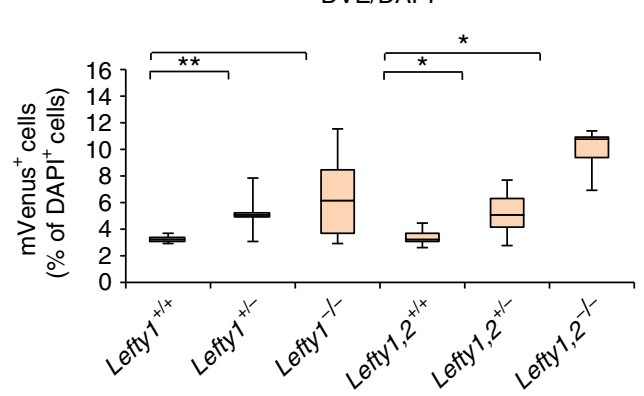

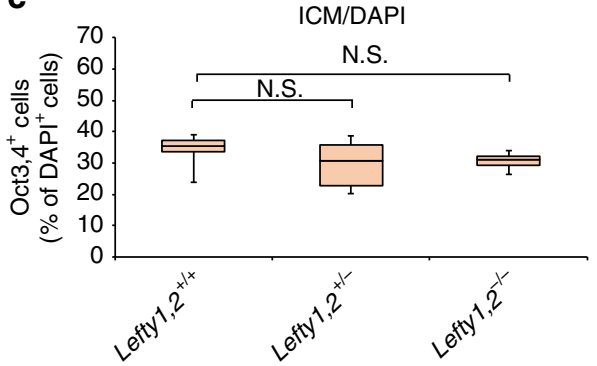

e

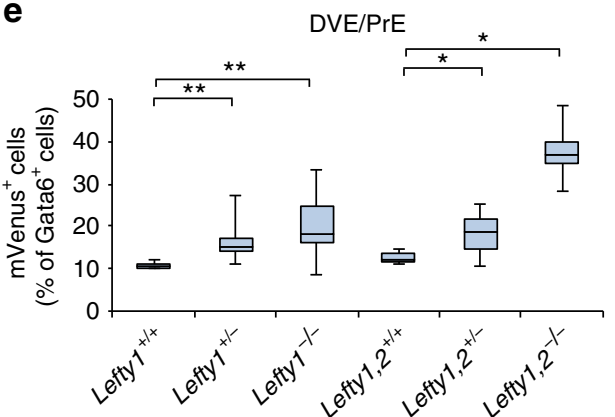

Fig. 4 Lefty 1 and Lefty 2 restrict the number of prospective DVE cells. a The number of prospective DVE cells [GATA6 ${ }^{+}$cells expressing the Lefty1( $m V$ Venus) BAC transgene] was examined in WT, Lefty $1^{-/-}$, and Lefty $1,2^{-/-}$embryos at E4.5. The embryos were subjected to immunofluorescence staining for mVenus and GATA6. Scale bars, $50 \mu \mathrm{m}$. Arrowheads and double-headed arrows indicate mVenus ${ }^{+}$cells (prospective DVE cells). b-e Summary of the number of PrE cells (GATA6 ${ }^{+}$cells) as a percentage of total cells (b), the number of ICM cells positive for Oct3/4 staining as a percentage of total cells (c) (Supplementary Fig. 5c), the number of prospective DVE cells as a percentage of total cells (d), and the number of prospective DVE cells as a percentage of total PrE cells (e) in embryos of the indicated genotypes at E4.5. Data are presented as box-and-whisker plots (first and third quartile, the line represents the median; whiskers: minimum to maximum). ${ }^{\star} P<0.05$, ${ }^{\star \star} P<0.01$; NS, not significant $(t$ test)

region remote from $\mathrm{L}_{1}{ }^{\mathrm{epi}}$ cells ${ }^{8}$. Unfortunately, it is not technically feasible to address the role of Lefty1 in L ${ }^{\text {epi }}$ cells directly, given that a Cre transgene active specifically in E3.5 epiblasts is not currently available (the expression of zygotic Sox2-Cre ${ }^{29}$ is not sufficiently early). Nonetheless, it is of note that the number of prospective DVE cells was increased to a markedly greater extent in Lefty $1,2^{-l-}$ embryos than in Lefty $1^{-/-}$embryos. Whereas Lefty 2 and Lefty 1 are both expressed in epiblast-fated cells at E3.5 (Supplementary Fig. $4 a-c$ ), they are expressed in different domains at E4.5, suggesting that Lefty1 and Lefty2 in epiblast-fated cells at E3.5 regulate the number of future DVE cells.

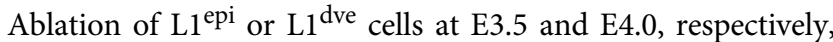
resulted in the initiation of Lefty 1 expression in remaining cells that presumably took over the role of the ablated cells. Injection of Nodal mRNA into a single cell of E3.2 embryos induced Lefty1 expression, but did not increase the number of $\mathrm{L}_{1} \mathrm{epi}^{\mathrm{ep}}$ cells. Together, these results suggest that selection of both $\mathrm{L}^{\mathrm{epi}}$ and $\mathrm{L} 1{ }^{\mathrm{dve}}$ cells is random and regulated (Fig. 7c). Consistent with this notion, the positions of $\mathrm{L}^{\text {epi }}{ }^{\text {cells at } \mathrm{E} 3.5}$ and of $\mathrm{L}^{\text {dve }}{ }^{\text {cells at }}$ E4.0 appear random, although $\mathrm{L} 1{ }^{\text {dve }}$ cells eventually occupy the future anterior side of the PrE at E4.5. Furthermore, embryos with Nodal mRNA injected into a single cell developed a normal $\mathrm{A}-\mathrm{P}$ axis at E6.5, suggesting that the A-P axis is established 
normally even if an ectopic cell is chosen to become an $\mathrm{L} 1^{\text {epi }}$ or $\mathrm{L} 1{ }^{\text {dve }}$ cell. Overall, our data suggest that selection of prospective DVE cells is both random and regulated, and that there may be no fixed prepattern for the future A-P axis before the blastocyst stage, although some cellular asymmetries along the future A-P axis have been detected around E5.5 (refs. 30,31). Further

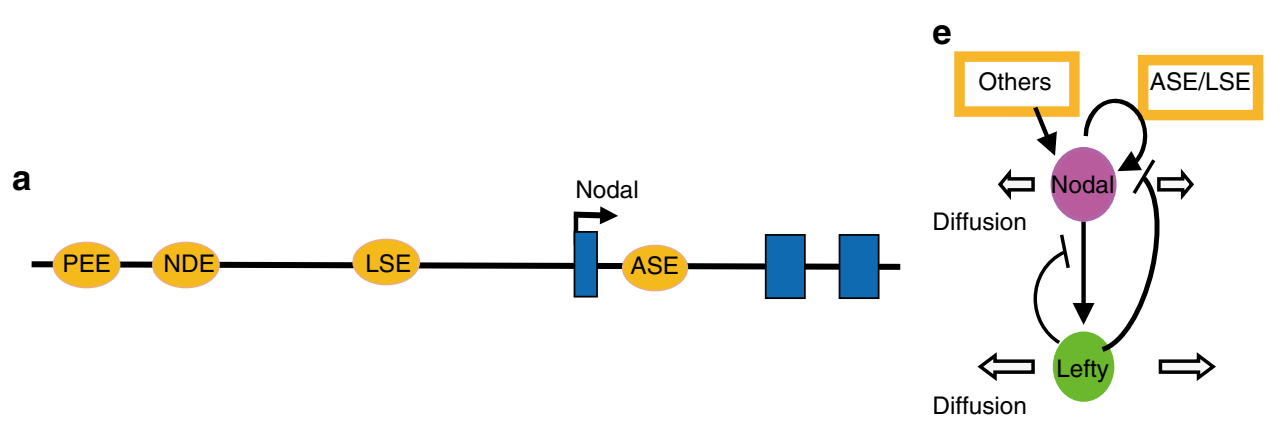

b

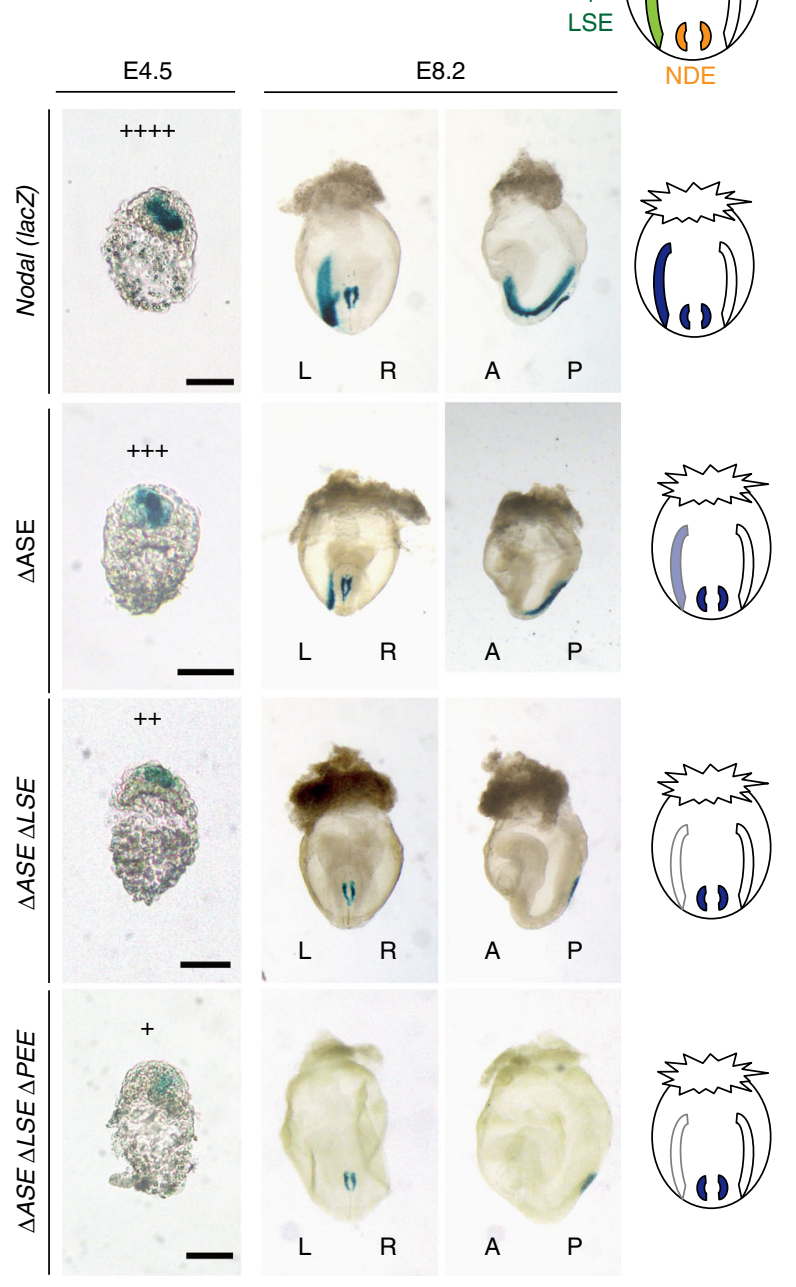

C

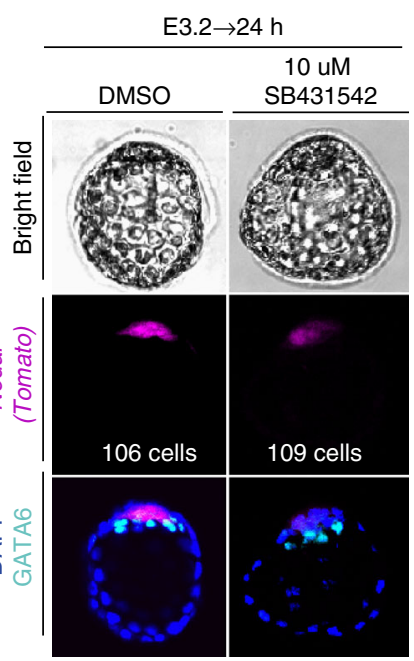

d

E4.5 Nodal(lacZ)

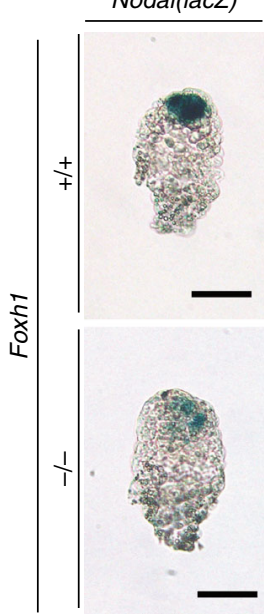

Fig. 5 Regulation of Nodal expression in peri-implantation embryos. a Four transcriptional enhancers-ASE, LSE, NDE, and PEE-contribute to regulation of Nodal expression. b Expression of Nodal(lacZ) BAC transgenes containing all enhancers or lacking either ASE alone, ASE and LSE, or ASE, LSE, and PEE was determined in embryos at E4.5 and E8.2 by X-gal staining. Scale bars, $50 \mu \mathrm{m}$. In E4.5 embryos, the relative levels of Nodal expression in the different embryos are indicated by plus signs. Frontal and lateral views are shown for E8.2 embryos. X-gal ${ }^{+}$regions are schematically summarized in diagrams on the right. Note that ASE and LSE are active in the lateral plate mesoderm, whereas NDE is active in the node ${ }^{40}$. c E3.2 embryos harboring a Nodal(Tomato) BAC transgene were cultured for $24 \mathrm{~h}$ with $10 \mu \mathrm{M}$ SB431542 or dimethyl sulfoxide (DMSO) vehicle and were then examined for Tomato and GATA6

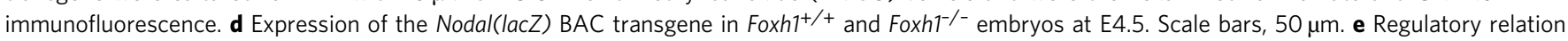
between Nodal and Lefty at the peri-implantation stage. The genes constitute a SELI system, as they do for L-R patterning at E8.0 
a

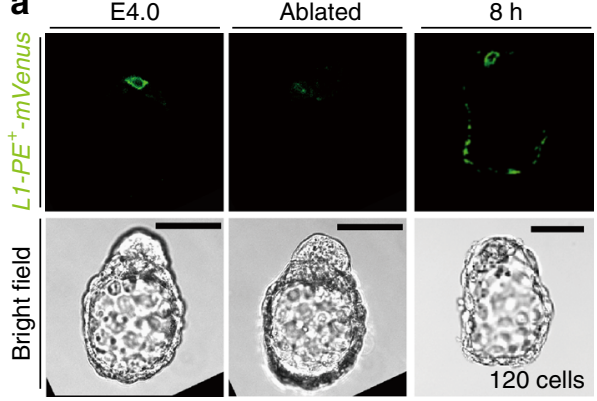

C

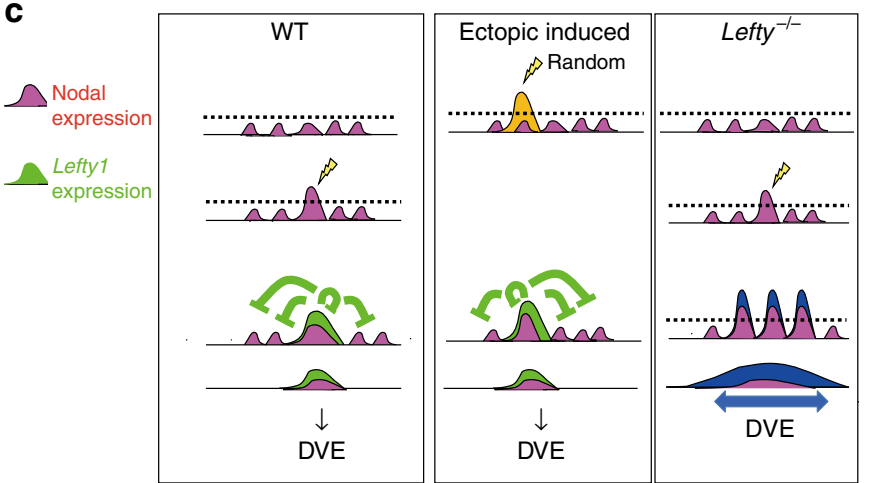

b

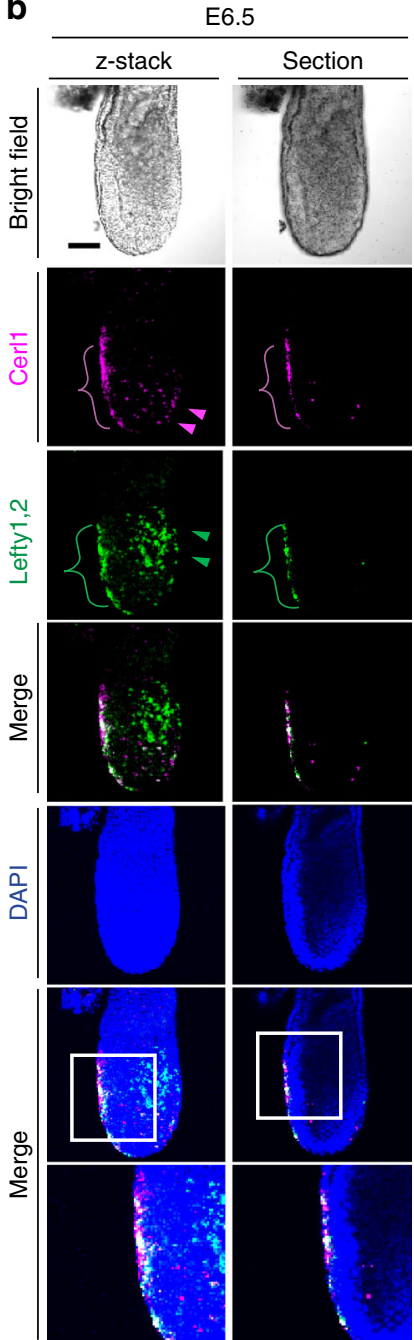

Fig. 7 Ablation of $L 1^{\text {dve }}$ cells at E4.0 results in the appearance of new $L 1^{\text {dve }}$ cells and does not impair A-P patterning. a All $\mathrm{mVenus}^{+}$cells $\left(\mathrm{L} 1^{\text {dve }}\right.$ cells) were removed by laser ablation from an E4.0 embryo harboring an $L 1-P E^{+}-m V e n u s$ transgene (Fig. 1b), after which the embryo was cultured for $8 \mathrm{~h}$ and then subjected to immunofluorescence staining for mVenus. Note that a new mVenus ${ }^{+}$cell had appeared by $8 \mathrm{~h}$ after the ablation. Scale bars, $50 \mu \mathrm{m}$. $\mathbf{b}$ After culture, an embryo such as that in a was transferred to a pseudopregnant mouse, allowed to develop until E6.5, and then recovered for immunofluorescence staining of A-P markers. Lefty1 and Cerl1 were detected in the AVE, suggesting that a normal A-P axis was established. Arrowheads indicate Cer $11^{+}$definitive endoderm cells in magenta, and Lefty $2^{+}$definitive ectoderm cells in green. The boxed regions of the merged images are shown at higher magnification in the images immediately below. c Model for the spatial distribution of Nodal expression and Lefty1 expression in a peri-implantation embryo based on observations in the present study. In the WT embryo (left panel), a cell that first expresses Nodal beyond a threshold level (dotted line) begins to express Lefty1. The Lefty1 protein then produced rapidly represses Nodal signaling in nearby cells, preventing them from expressing Lefty1. Injection of Nodal mRNA into a cell (middle panel) induces expression of Lefty1. In the absence of Lefty (right panel), a larger number of cells manifest Nodal expression or activity beyond the threshold and are fated to become DVE. See text for further details

Nodal(Tomato) BAC transgenes were constructed from RP23-322L8 and RP23$55 \mathrm{~A} 6$, respectively, by replacement of exon 1 of each gene with tdTomato. Nodal (lacZ) BAC transgenes lacking either ASE alone, ASE and LSE, or ASE, LSE, and PEE were constructed from a Nodal(lacZ) BAC ${ }^{32}$. An Oct3/4(mTomato) BAC transgene was constructed by insertion of the coding sequence for $m$ Tomato after the initiation codon of the mouse Oct3/4 BAC clone RP23-38P5. Recombinant $\mathrm{BAC}$ clones were generated with the use of the highly efficient recombination system for Escherichia coli ${ }^{33}$. BAC DNA was prepared by $\mathrm{CsCl}$ centrifigation and was linearized before microinjection ${ }^{34}$. Transgenic mice were generated as described previously ${ }^{15}$. Other mice used in this study have been reported: Lefty $1^{+/-}$ (ref. ${ }^{35}$ ), Foxh1 ${ }^{+/-}$(ref. ${ }^{36}$ ), Nodal ${ }^{+/-}$(ref. ${ }^{37}$ ), Nodal(lacZ) BAC ${ }^{32}$, and Foxh1-IreslacZ $\mathrm{BAC}^{38}$. Lefty $1,2^{+/-}$mice were generated as described in Supplementary Fig. 5a. All transgenic mice were generated in C57BL6 and C3H F1 hybrid mice, whereas Lefty $1,2^{+-}$mice were under the C57BL/129 mixed background. All mouse experiments were approved by the relevant committees of Osaka University and RIKEN Center for Developmental Biology, license numbers FBS-12-019 and AH28-01.
X-gal staining. Transgenic embryos were stained with the X-gal (5-bromo-4chloro-3-indolyl- $\beta$-D-galactopyranoside) substrate ${ }^{26}$.

Immunofluorescence analysis. Embryos were recovered in phosphate-buffered saline (PBS) and staged on the basis of their morphology. They were fixed for $15 \mathrm{~min}$ at room temperature in PBS containing 4\% paraformaldehyde, washed twice with PBS, permeabilized for $20 \mathrm{~min}$ at room temperature with $0.2 \%$ Triton X100 in PBS, and incubated first for $1 \mathrm{~h}$ at room temperature with TSA blocking reagent (Perkin-Elmer) and then overnight at $4{ }^{\circ} \mathrm{C}$ with primary antibodies diluted in blocking reagent. They were then washed three times with PBS before incubation with secondary antibodies diluted in blocking reagent. Nuclei were stained by incubation for $30 \mathrm{~min}$ at room temperature with DAPI (1/2000 dilution in PBS) (Wako). All images were acquired with the use of a laser-scanning confocal microscope system (FV1000, Olympus) and a UPLSAPO 20× objective lens (numerical aperture, 0.75 ; Olympus). Primary and secondary antibodies applied for immunofluorescence staining are listed in Supplementary Table 1. 
Injection of mRNA. Capped synthetic mRNAs encoding Nodal, mTomato and Cre were generated by in vitro transcription from the Nodal/pSP64T, mTomato/PCS2 and Cre/PCS2 vectors with the use of an SP6 mMessage mMachine Kit (Ambion AM1340). Nodal $(35 \mathrm{ng} / \mu \mathrm{l})$ and $m$ Tomato $(100 \mathrm{ng} / \mu \mathrm{l})$ mRNAs were introduced into a single cell of E3.2 embryos with the use of a Piezo-expert microinjector (Eppendorf). Injected embryos were cultured for $1.5 \mathrm{~h}$ and then checked with an M205FC fluorescence stereomicroscope (Leica), with only those with a single mTomato-positive cell being studied further.

Whole-mount in situ hybridization. Whole-mount in situ hybridization was performed according to standard procedures ${ }^{39}$ with digoxigenin-labeled riboprobes specific for Cerll or Hex. Embryos were genotyped by polymerase chain reaction analysis of partially purified embryonic DNA.

Time-lapse microscopy and image processing. Peri-implantation embryos were recovered in modified Whitten's medium ${ }^{8}$ and then transferred to glass-bottom culture dishes (Mat Tk, P35G-0-14-C) in fresh medium for culture in a $\mathrm{CO}_{2}$ incubator. Time-lapse images were obtained with a Cell Voyager CV1000 CSU confocal system (Yokogawa). The images were acquired from multiple positions at 15 -min intervals and $3 \mu \mathrm{m}$ apart in the $z$-axis for optical sectioning with a $20 \times$ objective lens (Olympus UplanApo; numerical aperture, 0.70 ). Confocal images were processed with IMARIS (Bitplane) for analysis of cell behavior.

Laser ablation of cells. All mVenus ${ }^{+}$cells in E3.5 embryos harboring Lefty1

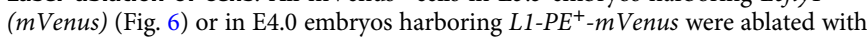
the use of a TCS SP5 multiphoton microscope (Leica). The embryos were immersed in Whitten's medium containing $20 \mathrm{mM}$ Hepes (pH 7.2). Membrane fluorescence of target cells was scanned in the confocal scanning mode with a 488$\mathrm{nm}$ argon laser. Target cells were ablated with a pulsed TiSa 1-W 800-nm laser at full power in the two-photon mode for 1 to $2 \mathrm{~s}$. The IR laser beam was restricted to the center of the cytoplasm of target cells in the region of interest (ROI) scan mode to prevent bleaching of membrane fluorescence and damage to neighboring cells. Successful ablation was confirmed by detection of changes to the cell membrane in the confocal scanning mode with the 488 -nm argon laser. Ablated cells were thus identified by the presence of debris at the cell membrane (Fig. 6c). All images were acquired with a Leica HCX APO $20 \times$ water-immersion objective lens (numerical aperture, 1.0)

Statistical analysis. The data were analyzed with $t$ test. A $P$ value of $<0.05$ was considered statistically significant and a $P$ value of $<0.01$ was highly significant.

Data availability. The authors declare that all data supporting the findings of this study are available within the article and its Supplementary Information files or from the corresponding author upon reasonable request.

Received: 31 July 2016 Accepted: 4 October 2017

Published online: 14 November 2017

\section{References}

1. Huynh, J. R. \& St Johnston, D. The origin of asymmetry: early polarisation of the Drosophila germline cyst and oocyte. Curr. Biol. 14, R438-R449 (2004).

2. Beddington, R. S. \& Robertson, E. J. Anterior patterning in mouse. Trends Genet. 14, 277-284 (1998).

3. Beddington, R. S. \& Robertson, E. J. Axis development and early asymmetry in mammals. Cell 96, 195-209 (1999).

4. Thomas, P. \& Beddington, R. Anterior primitive endoderm may be responsible for patterning the anterior neural plate in the mouse embryo. Curr. Biol. 6 , 1487-1496 (1996)

5. Rossant, J. \& Tam, P. P. Emerging asymmetry and embryonic patterning in early mouse development. Dev. Cell 7, 155-164 (2004).

6. Rossant, J. \& Tam, P. P. Blastocyst lineage formation, early embryonic asymmetries and axis patterning in the mouse. Development 136, 701-713 (2009).

7. Nowotschin, S. \& Hadjantonakis, A. K. Cellular dynamics in the early mouse embryo: from axis formation to gastrulation. Curr. Opin. Genet. Dev. 20, 420-427 (2010).

8. Takaoka, K., Yamamoto, M. \& Hamada, H. Origin and role of distal visceral endoderm, a group of cells that determines anterior-posterior polarity of the mouse embryo. Nat. Cell Biol. 13, 743-752 (2011).

9. Takaoka, K. et al. The mouse embryo autonomously acquires anterior-posterior polarity at implantation. Dev. Cell 10, 451-459 (2006).

10. Morris, S. A. et al. Dynamics of anterior-posterior axis formation in the developing mouse embryo. Nat. Commun. 3, 673 (2012).
11. Bedzhov, I. et al. Development of the anterior-posterior axis is a self-organizing process in the absence of maternal cues in the mouse embryo. Cell. Res. 25, 1368-1371 (2015).

12. Hiramatsu, R. et al. External mechanical cues trigger the establishment of the anterior-posterior axis in early mouse embryos. Dev. Cell 27, 131-144 (2013).

13. Robertson, E. J. Dose-dependent Nodal/Smad signals pattern the early mouse embryo. Semin. Cell Dev. Biol. 32, 73-79 (2014).

14. Nowotschin, S. et al. The T-box transcription factor Eomesodermin is essential for AVE induction in the mouse embryo. Genes Dev. 27, 997-1002 (2013).

15. Saijoh, Y. et al. Distinct transcriptional regulatory mechanisms underlie leftright asymmetric expression of lefty-1 and lefty-2. Genes Dev. 13, 259-269 (1999).

16. Oki, S., Maehara, K., Ohkawa, Y. \& Meno, C. SraTailor: graphical user interface software for processing and visualizing ChIP-seq data. Genes. Cells. 19, 919-926 (2014).

17. Kim, S. W. et al. Chromatin and transcriptional signatures for Nodal signaling during endoderm formation in hESCs. Dev. Biol. 357, 492-504 (2011).

18. Saijoh, Y. et al. Left-right asymmetric expression of lefty2 and nodal is induced by a signaling pathway that includes the transcription factor FAST2. Mol. Cell 5, 35-47 (2000).

19. Chu, J. \& Shen, M. M. Functional redundancy of EGF-CFC genes in epiblast and extraembryonic patterning during early mouse embryogenesis. Dev. Biol. 342, 63-73 (2010).

20. Chu, J. et al. Non-cell-autonomous role for Cripto in axial midline formation during vertebrate embryogenesis. Development 132, 5539-5551 (2005).

21. Lee, G. H. et al. A GPI processing phospholipase A2, PGAP6, modulates Nodal signaling in embryos by shedding CRIPTO. J. Cell. Biol. 215, 705-718 (2016).

22. Yamamoto, M. et al. Antagonism between Smad1 and Smad2 signaling determines the site of distal visceral endoderm formation in the mouse embryo. J. Cell Biol. 184, 323-334 (2009).

23. Perea-Gomez, A. et al. Nodal antagonists in the anterior visceral endoderm prevent the formation of multiple primitive streaks. Dev. Cell 3, 745-756 (2002).

24. Nakamura, T. et al. Generation of robust left-right asymmetry in the mouse embryo requires a self-enhancement and lateral-inhibition system. Dev. Cell 11, 495-504 (2006).

25. Wang, Y., Wang, X., Wohland, T. \& Sampath, K. Extracellular interactions and ligand degradation shape the nodal morphogen gradient. Elife 5, el3879 (2016).

26. Adachi, H. et al. Determination of left/right asymmetric expression of nodal by a left side-specific enhancer with sequence similarity to a lefty-2 enhancer. Genes Dev. 13, 1589-1600 (1999).

27. Norris, D. P. \& Robertson, E. J. Asymmetric and node-specific nodal expression patterns are controlled by two distinct cis-acting regulatory elements. Genes Dev. 13, 1575-1588 (1999).

28. Granier, C. et al. Nodal cis-regulatory elements reveal epiblast and primitive endoderm heterogeneity in the peri-implantation mouse embryo. Dev. Biol. 349, 350-362 (2011).

29. Hayashi, S., Lewis, P., Pevny, L. \& McMahon, A. P. Efficient gene modulation in mouse epiblast using a Sox2Cre transgenic mouse strain. Mech. Dev. 119, S97-S101 (2002).

30. Hoshino, H., Shioi, G. \& Aizawa, S. AVE protein expression and visceral endoderm cell behavior during anterior-posterior axis formation in mouse embryos: Asymmetry in OTX2 and DKK1 expression. Dev. Biol. 402, 175-191 (2015).

31. Yamamoto, M. et al. Nodal antagonists regulate formation of the anteroposterior axis of the mouse embryo. Nature 428, 387-392 (2004).

32. Uehara, M., Yashiro, K., Takaoka, K., Yamamoto, M. \& Hamada, H. Removal of maternal retinoic acid by embryonic CYP26 is required for correct Nodal expression during early embryonic patterning. Genes Dev. 23, 1689-1698 (2009).

33. Copeland, N. G., Jenkins, N. A. \& Court, D. L. Recombineering: a powerful new tool for mouse functional genomics. Nat. Rev. Genet. 2, 769-779 (2001).

34. Gong, S. et al. A gene expression atlas of the central nervous system based on bacterial artificial chromosomes. Nature 425, 917-925 (2003).

35. Meno, C. et al. lefty-1 is required for left-right determination as a regulator of lefty-2 and nodal. Cell 94, 287-297 (1998).

36. Yamamoto, M. et al. The transcription factor FoxH1 (FAST) mediates Nodal signaling during anterior-posterior patterning and node formation in the mouse. Genes Dev. 15, 1242-1256 (2001).

37. Wu, Q. et al. Nodal/activin signaling promotes male germ cell fate and suppresses female programming in somatic cells. Development 140, 291-300 (2013).

38. Shiratori, H., Yashiro, K., Shen, M. M. \& Hamada, H. Conserved regulation and role of Pitx2 in situs-specific morphogenesis of visceral organs. Development 133, 3015-3025 (2006) 
39. Wilkinson, D. G. Whole mount in situ hybridization of vertebrate embryos. In In Situ Hybridization: A Practical Approach 2nd edn. (IRL Press, 1992).

40. Krebs, L. T. et al. Notch signaling regulates left-right asymmetry determination by inducing Nodal expression. Genes Dev. 17, 1207-1212 (2003).

\section{Acknowledgements}

We thank A. Fukumoto, Y. Uegaki, K. Ohnishi-Sugimura, E. Kajikawa and K. Miyama for technical assistance. This work was also supported by a grant from CREST (Core Research for Evolutional Science and Technology) of JST as well as by a Grant-in-Aid from the Ministry of Education, Culture, Sports, Science, and Technology of Japan (no. 17H01435). K.T. was supported by KAKENHI Grants-in Aid for Scientific Research on Innovative Areas (no. 15H01511 and 24116706) from the Japan Society for the Promotion of Science and KAKENHI Grants-in Aid for Young Scientists (A) (no. 24687028).

\section{Author contributions}

The project was planned, the experiments were designed, and the manuscript was written by K.T. and H.H. Most experiments were performed and the data analyzed by K.T. Transgenes were constructed by H.N.

\section{Additional information}

Supplementary Information accompanies this paper at doi:10.1038/s41467-017-01625-X.
Competing interests: The authors declare no competing financial interests.

Reprints and permission information is available online at http://npg.nature.com/ reprintsandpermissions/

Publisher's note: Springer Nature remains neutral with regard to jurisdictional claims in published maps and institutional affiliations.

(c) (i) Open Access This article is licensed under a Creative Commons Attribution 4.0 International License, which permits use, sharing, adaptation, distribution and reproduction in any medium or format, as long as you give appropriate credit to the original author(s) and the source, provide a link to the Creative Commons license, and indicate if changes were made. The images or other third party material in this article are included in the article's Creative Commons license, unles indicated otherwise in a credit line to the material. If material is not included in the article's Creative Commons license and your intended use is not permitted by statutory regulation or exceeds the permitted use, you will need to obtain permission directly from the copyright holder. To view a copy of this license, visit http://creativecommons.org/ licenses/by/4.0/.

(c) The Author(s) 2017 